\title{
BMJ Open Pilot study protocol to inform a future longitudinal study of ageing using linked administrative data: Healthy AGeing in Scotland (HAGIS)
}

\author{
Elaine Douglas, ${ }^{1}$ Alasdair Rutherford, ${ }^{2}$ David Bell ${ }^{1}$
}

To cite: Douglas E,

Rutherford A, Bell D. Pilot study protocol to inform a future longitudinal study of ageing using linked administrative data: Healthy AGeing in Scotland (HAGIS). BMJ Open 2018;8:e018802. doi:10.1136/ bmjopen-2017-018802

- Prepublication history and additional material for this paper are available online. To view these files, please visit the journal online (http://dx.doi. org/10.1136/bmjopen-2017018802).

Received 21 July 2017

Revised 10 November 2017 Accepted 14 November 2017

CrossMark

${ }^{1}$ Stirling Management School, University of Stirling, Stirling, UK ${ }^{2}$ Faculty of Social Sciences, University of Stirling, Stirling, UK

Correspondence to

Dr Elaine Douglas;

elaine.douglas@stir.ac.uk

\section{ABSTRACT}

Introduction Population ageing is a welcome testament to improvements in the social, economic and health circumstances over the life course. However, these successes necessitate that we understand more about the pathways of ageing to plan and cost our health and social care services, to support our ageing population to live healthier for longer and to make adequate provisions for retirement. Longitudinal studies of ageing facilitate such understanding in many countries around the world. Scotland presently does not have a longitudinal study of ageing, despite dramatic increases to its ageing population and its poor health record. Healthy AGeing in Scotland (HAGIS) constitutes the launch of Scotland's first comprehensive longitudinal study of ageing.

Methods A sample of 1000 people aged $50+$ years will be invited to take part in a household social survey. The innovative sampling procedure used administrative data to identify eligible households. Anonymised survey responses will be linked to administrative data.

Ethics and dissemination Ethics approval was obtained from the host institution for the study design and from the Public Benefits and Privacy Panel for administrative data linkage. Anonymised survey data will be deposited with the UK Data Service. A subset of survey data, harmonised with other global ageing studies, will be available via the Gateway to Global Aging platform. These data will enable powerful cross-country comparisons across the social, economic and health domains that will be relevant for national and international research. Research publications from the HAGIS team will be disseminated through journal articles and national and international conferences. The findings will support current and future research and policy debate on ageing populations.

\section{INTRODUCTION}

Around the world people are living longer. ${ }^{1}$ This success brings both opportunities and risks to individuals, families and societies. It may challenge our assumptions and expectations of older people. Although life expectancy is generally increasing, the ageing process varies within and between groups of individuals. ${ }^{2}$ Our genetic makeup and exposure to different physical, social and economic environments lead to wide variation
Strengths and limitations of this study

The pilot study will test the use of administrative data in two ways:

The use of health register data as a sampling frame.

- Linkage of the survey to a range of administrative datasets.

- The use of health register data as a sampling frame is novel, and the pilot will establish the feasibility of this approach for future waves of the study, in particular, the optimisation of fieldwork time and costs and implications of survey non-response.

- The linkage of the survey to administrative datasets will:

Test the feasibility and acceptability of linking a social survey of older people to administrative data by relevant ethics committees, administrative data custodians (eg, the Public Benefit and Privacy Panel) and study participants. Produce a longitudinal/survival dataset when linked to the cross-sectional pilot survey data.

- The harmonised pilot survey data offers powerful cross-country comparisons across the social, economic and health domains that will be relevant for national and international policy debate from the outset.

- The benefits of data linkage are subject to the successful matching of the survey respondents to their administrative health records; therefore, this may limit the use of such data as a sample frame.

in economic and health outcomes. These outcomes will have a significant impact on many policy areas, not least, retirement planning and pension savings, working patterns and housing and the provision of health and social care services. Understanding pathways and processes of ageing, and the instrumental factors for living healthy lives for longer, is perhaps the most salient research area of our time.

Scotland, too, has an ageing population. The overall population is projected to increase to 5.7 million by 2039 , from 
5.3 million in 2015 . This increase will be accompanied by dramatic changes in its age structure. ${ }^{3}$ There is expected to be an $85 \%$ increase in those aged $75+$ years, a $59 \%$ increase in those aged $65+$ years, yet a $4 \%$ decrease in those aged 16-64 years by 2039. Life expectancy in Scotland has increased over the last three decades, although at a slower rate than other UK nations. ${ }^{4}$ Life expectancy at age 65 years has reached 17.2 and 19.5 additional years for men and women, respectively.

Lifespan variation, a measure of inequality at age of death, has largely been decreasing across Western Europe since the $1950 \mathrm{~s} .{ }^{5}$ This trend generally occurs in countries with a higher life expectancy and where rates of premature mortality have been reduced. Yet in Scotland, lifespan variation for men has increased, although slightly, since 1989. For women, the rate of decline in lifespan variation has slowed. Scotland remains the only country in Western Europe where women have a lifespan variation in excess of 10 years. ${ }^{5}$

Scotland has a poor health record, in terms of the prevalence of ill health and in its distribution. A quarter of Scotland's adult population have at least one long-term health condition and a further $25 \%$ have multiple longterm conditions. ${ }^{6}$ Multiple long-term health conditions are generally socially graded and are more common in older adults. Around a third $(34 \%)$ of those living in the most deprived areas have multiple long-term conditions, in comparison with approximately one-fifth $(18 \%)$ of those living in the least deprived areas. The prevalence of multiple long-term conditions increases with age, such that almost half $(47 \%)$ of those aged 65-74 years have multiple long-term conditions rising to $59 \%$ of those aged $75+$ years. High rates of non-communicable disease, such as cardiovascular disease and chronic respiratory disease, and higher prevalence of dementia indicate that chronic disability will become a major problem. Increasing numbers of people with chronic disease or long-term disabilities will place increasing demands on both health and social care services. Primary, secondary and tertiary preventions of chronic disease is imperative to reduce the projected personal and societal burden. Health and social care costs are likely to increase without substantive improvements in healthy life expectancy and/or evidence-based policy responses to increasing demands. ${ }^{7}$

An ageing population has many economic implications at an individual and societal level. For example, after adjustment for increases in the state pension age, the number of people of pensionable age is projected to increase from around 300 per 1000 working age population in 2012 to 400 in 2037. ${ }^{3}$ This indicates a significant increase in the old-age dependency ratio and has implications for working patterns and retirement planning for older people. For example, both overemployment and underemployment are associated with retirement timing. ${ }^{8}$ Yet, changes to working patterns in older people, including the older self-employed, are not well understood. This has wide-ranging policy implications including how to support longer (healthier) working lives, retraining older workers and planning and timing of retirement. ${ }^{7}$

Longitudinal studies are ideal for studying the dynamics of ageing and, significantly, to explore issues of causality. Scotland does not presently have a comprehensive longitudinal study of ageing, which makes it unusual in Europe. The English Longitudinal Study of Ageing (ELSA) was established in 2002 and has recently reported results from its seventh wave. ${ }^{9}$ The Irish Longitudinal Study of Ageing has now reported on its third wave, and the Northern Ireland Cohort for Longitudinal Study of Ageing (NICOLA) was launched in 2014. ${ }^{10}$ The Survey of Health, Ageing and Retirement in Europe is a multidisciplinary and cross-national survey comprising 27 European countries in its seventh wave. ${ }^{11}$ Alongside other global ageing studies, these have produced a wealth of research publications to support understanding of ageing and to inform policy debate. ${ }^{12}$

A scoping study for a Scottish longitudinal study of ageing, commissioned by the Scottish Government (SG) and National Health Service (NHS), found widespread support among academics and policy makers. ${ }^{13}$ It was acknowledged that existing data sources are inadequate to address the key issues of Scotland's ageing population. In particular, the report highlighted the significant value of further understanding of labour market transitions and outcomes for older people in Scotland, how these are affected by health and disability and indeed how changing attitudes and expectations impact decision making. Scotland may be well placed to make substantive contributions to global ageing research due to its demographic profile, distinctive policy developments (within a UK context), wealth, its internationally recognised researchers and its access to administrative data linkage. ${ }^{14}$ The pilot study will recruit people aged 50 years and over to take part in a future longitudinal study of ageing. The pilot will test the acceptability and feasibility of using administrative data (1) as a sampling frame and (2) to add substantive value to the survey data collected. The study dates are from July 2015 to February 2018.

\section{METHODS AND ANALYSIS \\ Study aims}

Broadly, the overarching aims of HAGIS are to further the understanding of pathways of ageing in Scotland for academic and policy purposes, and in doing so, to improve health and socioeconomic outcomes for older people. ${ }^{15}$ We wish to contribute a valued ageing data resource and to generate methodological advances that will benefit other global ageing studies. We specifically wish the pilot survey to mark the start of Scotland's first comprehensive longitudinal study of ageing.

Thus, we aim to: 


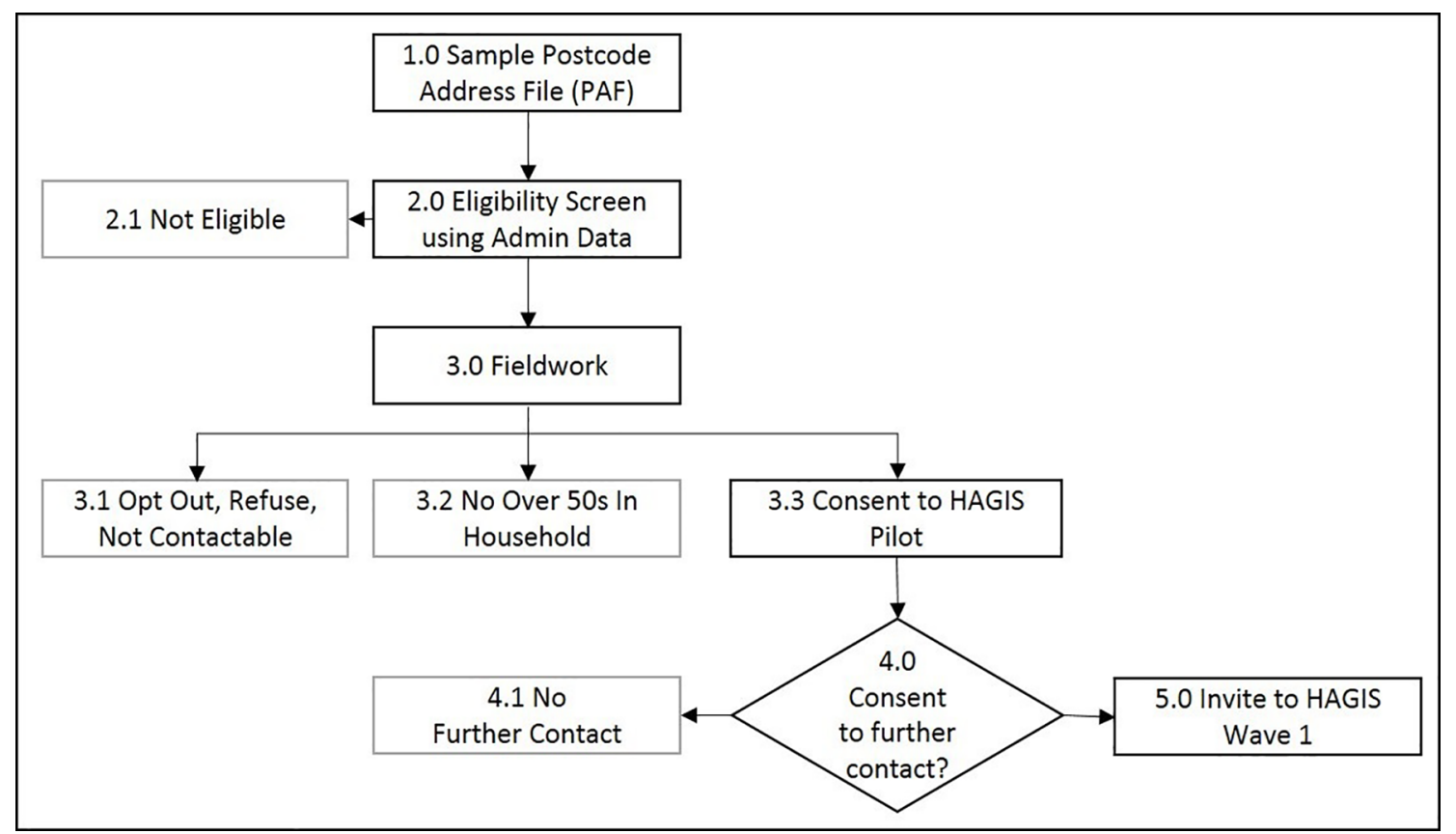

Figure 1 HAGIS pilot sampling and consent process.

1. Test the innovative sampling frame and screening procedures with a view to providing recommendations for sampling strategy for future full waves of HAGIS.

2. Determine the representativeness of the pilot respondents tothe Scottish population as a whole, using administrative data.

3. Collect baseline cross-sectional survey data $(n=1000)$.

4. Report on the acceptability (consent rates) of administrative data linkage to persons aged over 50 years in Scotland.

5. Produce an anonymised data resource for open access via the UK Data Service and Gateway to Global Aging. ${ }^{16}$

6. Inform the development of future waves of HAGIS (sample 7000 )

7. Contribute to national and international academic journals and conferences and to inform policy debate.

\section{Design and sample}

HAGIS will create a data resource to be made available for national and international research. ${ }^{15}$ It comprises a household social survey that will make innovative use of administrative data to screen households for eligibility and will link this initial cross-sectional survey data to longitudinal NHS health and local authority social care data. The four main components of the study are: screening the sample for study eligibility; conducting survey fieldwork (face-to-face household interview and self-completion questionnaire); linking the survey to administrative data; and depositing anonymised survey responses in national and international repositories for data sharing.

The pilot study will recruit 1000 participants aged 50 years or over from across mainland Scotland. A sample size of 1000 is sufficient to detect a 5 percentage point difference in outcomes with a prevalence of around $5 \%-10 \%$ by binary categories such as urban/rural, self-reported health, financial literacy levels, cognitive impairment and others (sample size per group of around 400 individuals, alpha $=0.05$, Power $=0.8$ ). The dataset will also be used to make comparisons with harmonised datasets such as ELSA, where detecting a 5 percentage point difference in outcomes with a prevalence of 15\%-20\% between the two study samples would require a per-study sample of $\sim 900$ individuals (alpha $=0.05$, Power $=0.8$ ). These prevalence rates provide examples of the effect sizes that could be detected but are broadly reflective of the prevalence of characteristics such as disability, informal care provision and receipt of social care. Future waves will recruit $\sim 7000$ respondents, allowing for comparisons between greater numbers of subgroups and bringing the sample in line with other longitudinal studies of ageing in the UK.

Sampling

An overview of the sampling process is included in figure 1. A two-stage cluster-sampling approach to identify a random sample of residential addresses from the Postcode Address File will be undertaken (see figure 1, step 1.0). Initially, Scotland will be stratified by mainland Scotland datazones (small, relatively homogenous, geographical units of 500-1000 household residents ${ }^{17}$ ), classified into the $11^{\mathrm{i}}$ mainland Scottish Health Boards and assigned rural/urban indicators and Scottish Index of Multiple Deprivation (SIMD). Datazones will be selected with the probability proportionate to size as measured by the adult aged $50+$ population based on the Census 2011 data. Within each datazone, residential

${ }^{\mathrm{i}}$ There are 14 Scottish Health Boards. NHS Western Isles, NHS Orkney and NHS Shetland were excluded from the sampling frame. 
addresses will be ordered by postcode. A 'selection interval' will be calculated equal to the integer value of the total number of addresses within each datazone, divided by the number of addresses to be sampled from within that datazone. A starting point will be chosen at random and then addresses will be sampled using the selection interval until the quota of 17 addresses for that datazone are met. This work will be conducted by UK Geographics ${ }^{18}$ on behalf of our fieldwork agency, FACTS International. ${ }^{19}$

The National Records for Scotland will screen the selected household addresses for eligibility to the study (see figure 1, step 2.0). That is, they will identify households with at least one resident aged 50 years or over. Within each selected household, eligible sample members include: (1) all adults aged 50 years or over and (2) the partners of adults aged 50 years or over where the partners are at least 45 years. No personal information will be exchanged between National Records for Scotland and the study team. Permission to conduct the eligibility screening has been granted by the Public Benefits and Privacy Panel (PBPP) ${ }^{20}$ (see online supplementary appendix 2).

\section{Recruitment and fieldwork}

An invitation letter, information leaflet and opt-out postcard will be sent to all eligible households. This will include details on taking part in the study, how to get more information (including a freephone number direct to the HAGIS Project Manager) or how to opt out. Eligible residents will be notified that an interviewer will visit their household shortly (approximately 10-14 days after receipt of invitation to give respondents sufficient time to opt-out, if desired) to arrange a suitable time for an interview.

Fieldwork comprises a face-to-face Computer Assisted Personal Interview (CAPI) and self-completion of a shorter, additional questionnaire. The respondent can choose to complete the self-completion questionnaire at the end of the CAPI using the tablet provided or later via a web link or paper copy (with reply-paid envelope). The face-to-face interview is expected to take around 1.5-2 hours per household and may be split over more than one visit if required.

\section{Consent to participate}

Consent to participate will comprise: consent to participate in the pilot survey interview (figure 1, step 3.3); consent to link survey responses to administrative data; and consent to be recontacted at a later date to take part in future waves of HAGIS.

\section{Consent to participate in the survey interview}

Around 7-10 days after receipt of the invitation letter, and in the absence of any opt-out notification, interviewers will approach eligible households to seek their informed consent to take part in the interview. This explicitly includes consent for anonymised survey responses to be used by others (ie, beyond the HAGIS study team) for research purposes.

\section{Consent to data linkage}

Participants will be asked for consent to link their survey responses to administrative data: NHS Health (including dental); social care census; education; Department of Work and Pensions records; and Her Majesty's Revenue and Customs (HMRC) records. Participants may consent to some, none or all administrative record linkage. The HAGIS pilot is an Administrative Data Research Network (ADRN)-approved study (see online supplementary appendix 3 ).

\section{Consent for further contact}

As part of the interview, respondents will be asked for consent to be recontacted for potential involvement in future waves of the study.

The consent obtained will determine the level of participation in the HAGIS pilot study (see figure 1): (1) pilot survey only (step 4.1); pilot survey and data linkage only (step 4.2); pilot survey, data linkage and further contact (step 4.3); or pilot survey only and further contact (step 4.4). Those who consent to further contact, irrespective of data linkage consent, will be invited to take part in the HAGIS Wave 1 (step 6.0).

\section{Survey instrument}

The HAGIS survey is largely based on the ELSA and NICOLA questionnaires and therefore is widely comparable (see online supplementary appendices 4 and 5). The survey instrument contains validated questions covering a wide range of topics including cognitive health, financial literacy, personality and standard of living (see online supplementary appendix 4 ). This will ensure that the study data will (1) create a valid and valuable data resource and (2) be harmonised with other global ageing studies to support cross-country comparisons. The topics covered in the questionnaires are outlined in table 1.

\section{Data transfer}

The CAPI survey will be collected in state-of-the-art data collection software, Confirmit Horizons. The data will be held securely at Rackspace, a secure UK datacentre certified to ISO 27001, 9001, 14001, 18001, SOC3 and is also Payment Card Industry (PCI) compliant. The survey data, including personal data, will be transferred between the fieldwork agency and the University of Stirling using Pretty Good Privacy encrypted, self-decrypting archives and accessed through secure file transfer protocol servers. A Privacy Impact Assessment was conducted in 2016 and presented for approval by the PBPP.

\section{Data linkage}

Survey responses, where consent is given, will be linked to the administrative data sources listed below. 
Table 1 Content of the main CAPI and self-completion questionnaires

\begin{tabular}{ll}
\hline Main CAPI questionnaire & Self-completion questionnaire \\
\hline Demographics & Internet and TV use \\
\hline Social circumstances & Social activities \\
\hline Employment & Support from family and friends \\
\hline Income and assets & Transport \\
$\begin{array}{l}\text { Expectations and } \\
\text { retirement }\end{array}$ & Current financial situation \\
\hline Financial literacy & Health and health behaviours \\
Physical health & Personality \\
Cognitive health & \\
Health behaviour & \\
\hline
\end{tabular}

\section{Activities of daily living}

and helpers

Social participation

CAPI, Computer Assisted Personal Interview.

Health and social care

The NHS Scottish Medical Record (SMR) linkage will be sought from 2005 onwards to include: SMR00 Outpatients; SMR01 Inpatients \& Day Cases; SMR04 Mental Health; SMR06 Cancer Registration; Accident \& Emergency; and prescription data from the Prescribing Information System. Social Care Census data will be sought from 2010 onwards.

\section{Education}

Permission has been sought from the National Archives of Scotland and the Scottish Qualifications Authority to link respondents to their historical school qualifications.

\section{Department of Work and Pensions (DWP) and HMRC}

We will seek permission to link survey responses to DWP and HMRC data. Receipt of welfare benefits, income tax and national insurance contributions have a range of policy implications, relating to the planning of taxes, pensions and benefits.

Rates of consent to data linkage will be reported at the end of the study and will inform projections of coverage for future waves of HAGIS where the sample size will dramatically increase.

\section{Materials}

The HAGIS questionnaires (see online supplementary appendices 4 and 5), participant information leaflet, invitation letter and other study materials will be made available from the HAGIS website.

\section{Weighting}

Although this is a pilot version of the HAGIS study, we have tried to replicate as far as possible the processes that would be involved in implementing a first full wave of the study. This includes sample weighting. Even though the process of weighting may reduce bias in our estimates, standard errors will be significantly larger than in a full wave, given that our pilot sample size is only around 1000. Our approach has first been to account for the design weights in the survey (which are given by the population aged $50+$ years in the mainland health boards) and second to apply calibration weighting to derive individual weights. Probability sampling weights will be derived with the aim of increasing precision and accounting for unit non-response by forcing sample-derived estimates to be consistent with known population totals. It is consistent with the approach that the SG recently discussed in its review of the weighting strategy to be applied to inhouse surveys in the future. ${ }^{21}$ The generalised raking procedures to derive sample weights, which are consistent with a set of external control totals and which minimise some measure of distance to the original design weights, ${ }^{22}$ will be applied. Control totals associated with age groups, sex, health board and SIMD will be used to implement the technique.

\section{Data analysis}

Statistical data analyses will depend on the specific research undertaking that will be addressed by the social, economic and health data made available by the HAGIS study. Detailed analyses will therefore be reported in the publication of each future study.

\section{ETHICS AND DISSEMINATION Ethics approval}

There were three key categories for ethical and information governance consideration: ethical approval of the overall HAGIS study (University of Stirling Ethics); approval for access to administrative data (ADRN); and scrutiny of proportionate information governance (PBPP). In particular, the ADRN and PBPP applications were required to approve our requirement to (1) screen the drawn household sample for eligibility against NHSCR records and (2) to link anonymised HAGIS survey responses to administrative data, where participant consent is given.

\section{Administrative Data Research Network}

The ADRN Panel approved the HAGIS study project proposal in January 2016 against four criteria: feasibility, academic merit, public benefit and privacy impact (PROJ065-HAGIS Study).

\section{Public Benefits and Privacy Panel}

The PBPP performs information governance scrutiny of requests for access to NHS Scotland health and social care data. ${ }^{20}$ The specific permissions sought, and granted, in this respect related to the screening of the drawn sample for eligibility and the survey data linkage to health and social care data. The panel approved the HAGIS (HAGIS 1516-0417) study application in May 2016. 


\section{Dissemination}

\section{Data sharing}

\section{UK Data Service}

HAGIS will provide a rich data resource to be used for future scientific research. Anonymised, shareable survey data from the HAGIS study will be deposited with the UK Data Service.

\section{Gateway to Global Aging}

The Gateway to Global Aging, ${ }^{23}$ a platform for household survey data on ageing, supports cross-country analyses. These include the USA (Health and Retirement Study), Mexico (Mexican Health \& Aging Study), China (China Health and Retirement Longitudinal Study), Japan (Japanese Study of Aging \& Retirement), India (Longitudinal Aging Study in India) in addition to the aforementioned British Isles and European ageing studies. HAGIS will join the Gateway to Global Aging on completion of data collection. The HAGIS study will be included in the Gateway's digital library where a harmonised subset of anonymised survey data will be available for international research.

Webinars, workshops and other knowledge exchange events to highlight the content, availability and access to HAGIS data will be undertaken.

Research findings from this study will be presented at national and international conferences and be reported in national and international peer-reviewed academic journals. HAGIS will engage with policy makers to inform social, economic and health policy debate on issues relevant to an ageing population. The HAGIS team have established connections with SG and have presented the HAGIS study to the SG at Victoria Quay, Edinburgh, in January 2017. Presentation of preliminary HAGIS pilot study findings to the SG will take place in late 2017. Further news and updates of research publications, events and workshops will be published on the HAGIS website. ${ }^{24}$

Over time, the overall research output from HAGIS is anticipated to be comparable with other ageing studies. To date, ELSA and the Gateway to Global Aging have published around 300 and 6000 research articles, respectively. ${ }^{25} 26$

Acknowledgements The authors would like to acknowledge support from lan Deary and Chloe Fawns-Ritchie (University of Edinburgh) in the development of the cognitive assessment, Elizabeth Lemmon (University of Stirling), the HAGIS Steering Group, Richard Suzmann (National Institute of Aging), James Smith (RAND), David Weir (University of Michigan), Ken Langa (University of Michigan) and Sharon Witherspoon (Nuffield Foundation).

Contributors DB and AR developed the overall research design and gained the funding. ED has been involved in all aspects of the study and wrote the first draft of this manuscript. All authors subsequently contributed and commented on the manuscript and approved the final version.

Funding This project was part-funded by the National Institute of Aging (RAG044535A) in the USA and was also part-funded by the Nuffield Foundation (OPD/42197), but the views expressed are those of the authors and not necessarily those of the Foundation.

Disclaimer The views expressed are those of the authors and not necessarily those of the Foundation.

Competing interests None declared.
Patient consent Detail has been removed from this case description/these case descriptions to ensure anonymity. The editors and reviewers have seen the detailed information available and are satisfied that the information backs up the case the authors are making.

Ethics approval The School Research Ethics Committee at the University of Stirling approved the overall ethical standards of the HAGIS study in October 2015 (see online supplementary appendix 1 ).

Provenance and peer review Not commissioned; externally peer reviewed.

Open Access This is an Open Access article distributed in accordance with the Creative Commons Attribution Non Commercial (CC BY-NC 4.0) license, which permits others to distribute, remix, adapt, build upon this work non-commercially, and license their derivative works on different terms, provided the original work is properly cited and the use is non-commercial. See: http://creativecommons.org/ licenses/by-nc/4.0/

(c) Article author(s) (or their employer(s) unless otherwise stated in the text of the article) 2018. All rights reserved. No commercial use is permitted unless otherwise expressly granted.

\section{REFERENCES}

1. World Health Organization WHO. Ageing and Health. 2016 http:// www.who.int/mediacentre/factsheets/fs404/en/ (accessed 16 May 2017).

2. Beard JR, Bloom DE. Towards a comprehensive public health response to population ageing. Lancet 2015;385:658-61.

3. National Records of Scotland, NRS. Scotland's population - the registrar general's annual review of demographic trends. 159 th edn. Scotland: National Records of Scotland, 2014.

4. Office for National Statistics. Life expectancy at birth and at age 65 by local areas in the United Kingdom. Statistical bulletin. 2015 http:// www.ons.gov.uk/peoplepopulationandcommunity/birthsdeathsand marriages/lifeexpectancies/bulletins/lifeexpectancyatbirthandatag e65bylocalareasintheunitedkingdom/2014-04-16 (accessed $16 \mathrm{Apr}$ 2014).

5. Seaman R, Leyland AH, Popham F. How have trends in lifespan variation changed since 1950? A comparative study of 17 Western European countries. Eur J Public Health 2016;26:360-2.

6. The Scottish Government. The Scottish Health Survey 2015. Vol. 1, 2016:303.

7. Government Office for Science. Future of an ageing population. 2016 https://www.gov.uk/government/publications/future-of-an-ageingpopulation.

8. Bell DNF, Rutherford AC. Older workers and working time. J Econ Ageing 2013;1-2:28-34.

9. Banks J, Batty D, Bridges S. ELSA Wave 7 The Dynamics of Ageing. 2016 http://www.ifs.org.uk/uploads/elsa/docs_w6/ELSA Wave 6 report.pdf.

10. QUB Centre for Public Health NO. About NICOLA | NICOLA | Queen's University belfast. 2016 http://www.qub.ac.uk/sites/NICOLA/ AboutNICOLAV (accessed 5 Sep 2017).

11. The Survey of Health, Ageing and Retirement in Europe (SHARE). Dates and facts. $2016 \mathrm{http} / / / \mathrm{www}$.share-project.org/organisation/ dates-facts.html (accessed 22 Jun 2017)

12. The Center for Economic and Social Research (CESR). Gateway to global aging data | publications. 2017 https://g2aging.org/?section= papers (accessed 7 Jun 2017).

13. Anderson $S$, Boyle $P$, Sharp CA Scottish longitudinal study of ageing: scoping study. 2008 http://www.gov.scot/Publications/2008/12/ $15150027 / 12$

14. Robertson JM, Bowes A, Gibson G, et al. Spotlight on Scotland: assets and opportunities for aging research in a shifting sociopolitical landscape. Gerontologist 2016;56:979-89.

15. HAGIS. HAGIS home - Healthy AGeing in Scotland (HAGIS). 2016 http://www.hagis.scot/ (accessed 5 Sep 2017).

16. Center for Economic and Social Research. Gateway to global aging data | downloads. $2015 \mathrm{https} / / /$ g2aging.org/?section=page\&pageid= 18 (accessed 8 Sep 2017).

17. Scottish Government. Scottish neighbourhood statistics guide. 2005 http://www.gov.scot/Publications/2005/02/20697/52626 (accessed 7 Jun 2017).

18. UK Geographics. http://www.ukgeographics.co.uk/about (accessed 18 Aug 2017).

19. Facts International. Award-winning market research from the UK's leading fieldwork provider. http://www.facts.uk.com/ (accessed 18 Aug 2017). 
20. Public Benefit \& Privacy Panel (PBPP). Public Benefit and Privacy Panel for Health and Social Care. http://www.informationgovernance. scot.nhs.uk/pbpphsc/home/about-the-panel/ (accessed 6 Jun 2017).

21. Scottish Government. Scottish population surveys centralised weighting project. 2013 http://www.gov.scot/Topics/Statistics/ About/Surveys/WeightingProjectReport (accessed 8 Sep 2017).

22. Deville J-C, Särndal C-E. Calibration estimators in survey sampling J Am Stat Assoc 1992;87:376-82.
23. Gateway to Global Aging Data. 2015. https://g2aging.org/ (accessed 22 Jun 2017)

24. Healthy Ageing In Scotland (HAGIS). http://www.hagis.scot/ (accessed 22 Jun 2017)

25. English Longitudinal Study of Ageing. http://www.elsa-project.ac.uk/ publications/case/related (accessed 22 Jun 2017).

26. Gateway to Global Aging Data. Publications. https://g2aging.org/? section=papers (accessed 22 Jun 2017). 